\title{
Unusual renal tumour: multilocular cystic renal cell carcinoma
}

\author{
Marta Morna Palmeiro, João Luz Niza, Ana Luisa Loureiro, \\ João Paulo Conceição e Silva
}

Department of Radiology, Instituto Português de Oncologia de Lisboa Francisco Gentil, Lisbon, Portugal

\section{Correspondence to Dr Marta Morna Palmeiro, palmeiro.marta@gmail.com}

Accepted 21 February 2016
CrossMark

To cite: Morna Palmeiro $\mathrm{M}$, Niza JL, Loureiro AL, et al. BMJ Case Rep Published online: [please include Day Month Year] doi:10.1136/ bcr-2016-214386

\section{SUMMARY}

Multilocular cystic renal cell carcinoma (MCRCC) is a rare presentation of renal cell carcinoma. Most patients are asymptomatic and frequently MCRCCs are detected incidentally. MCRCCs have good prognosis because of their low malignant potential. We report a case of a 39year-old woman who presented with mild right flank pain and normal laboratory data. On imaging examinations, a Bosniak III cystic lesion was detected in the lower third of the right kidney. She underwent right partial nephrectomy and histopathology showed a multilocular cystic renal cell carcinoma Fuhrman grade 1. In this article, we also present a review of the literature on MCRCC, highlight the correlation of the pathological and imaging characteristics of these low aggressive renal lesions, and underscore the importance of their recognition to prevent unnecessary radical surgery.

\section{BACKGROUND}

The 2004 WHO guidelines classify multilocular cystic renal cell carcinoma (MCRCC) as a uncommon variant of clear cell renal cell carcinoma (RCC), representing approximately $4 \%$ of all RCC. ${ }^{1}$

These neoplasms appear more commonly between the 2nd and 7th decades of life, being more frequent in males than in females. ${ }^{2}$ Usually, they have no associated symptoms, and are detected incidentally in most cases. ${ }^{3}$

MCRCCs characteristically presents as welldefined multilocular cystic tumours, composed of multiple cysts of different sizes and multiple septa, more frequently in the form of Bosniak type III lesions. ${ }^{4}$ They cannot be distinguished from other complex cystic renal lesions by imaging. Their final diagnosis is made by histopathological analysis after surgical resection, because of their typical findings, which are not always detected on biopsy. ${ }^{4} 5$

These rare RCCs have an indolent and a good outcome because of their low nuclear grade, commonly Fuhrman grade $1 .^{5}$ Thus, when a MCRCC is suspected, it should be treated with conservative surgery. 4

\section{CASE PRESENTATION}

A 39-year-old woman presented with a 4-week history of intermittent mild right flank pain. There was no relevant previous medical history. The patient had no significant weight or appetite loss, no fever, no hypertension and no haematuria. On initial examination, there was only a slight discomfort on right flank palpation, with no peritoneal reaction and no detection of palpable abdominal masses. There was no family history of neoplasms.

\section{INVESTIGATIONS}

Laboratory findings, including haemoglobin, white cell count, platelets, creatinine, lactate dehydrogenase and calcium blood levels, were normal.

An abdominal ultrasound was performed, which revealed a partially exophytic well-defined lesion in the lower third of the right kidney. This neoplasm showed heterogeneous echogenicity with anechoic cystic and hyperechoic solid areas (figure 1).

To further characterise this complex renal lesion, an abdominopelvic CT and abdominal MRI were performed.

On unenhanced CT, this lesion showed welldefined limits, predominant hydric density and a few fine septal calcifications (figure 2A). Administration of intravenous contrast demonstrated the multiloculated morphology of this tumour with multiple cysts separated by multiple thick and irregular septa showing measurable enhancement (figure 2B-E). No solid nodules were detected. These CT features were consistent with a Bosniak type III lesion. This patient also showed inferior vena cava duplication, a rare congenital vascular anatomic variation (figure 2 ).

On MRI, the lesion was also well circumscribed, showing a hypointense rim on T2-weighted (figure 3) and T1-weighted images (figure 4). The T2-weighted images demonstrated the multiloculated morphology of the lesion composed of multiple hyperintense cysts separated by multiple thick and irregular hypointense septa, without solid nodules (figure 3). The T1-weighted images showed signal intensity similar to that of the adjacent renal parenchyma (figure 4A). On in-phase and out-of-phase T1-weighted images (figure 4)

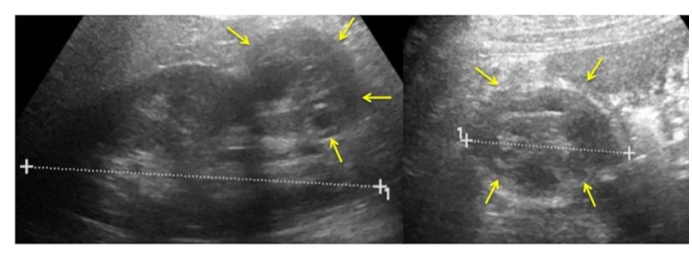

Figure 1 Abdominal ultrasound of a partially exophytic well-defined lesion detected in the lower third of the right kidney (arrows). This neoplasm showing heterogeneous echogenicity with anechoic cystic areas separated by hyperechoic solid septa. 


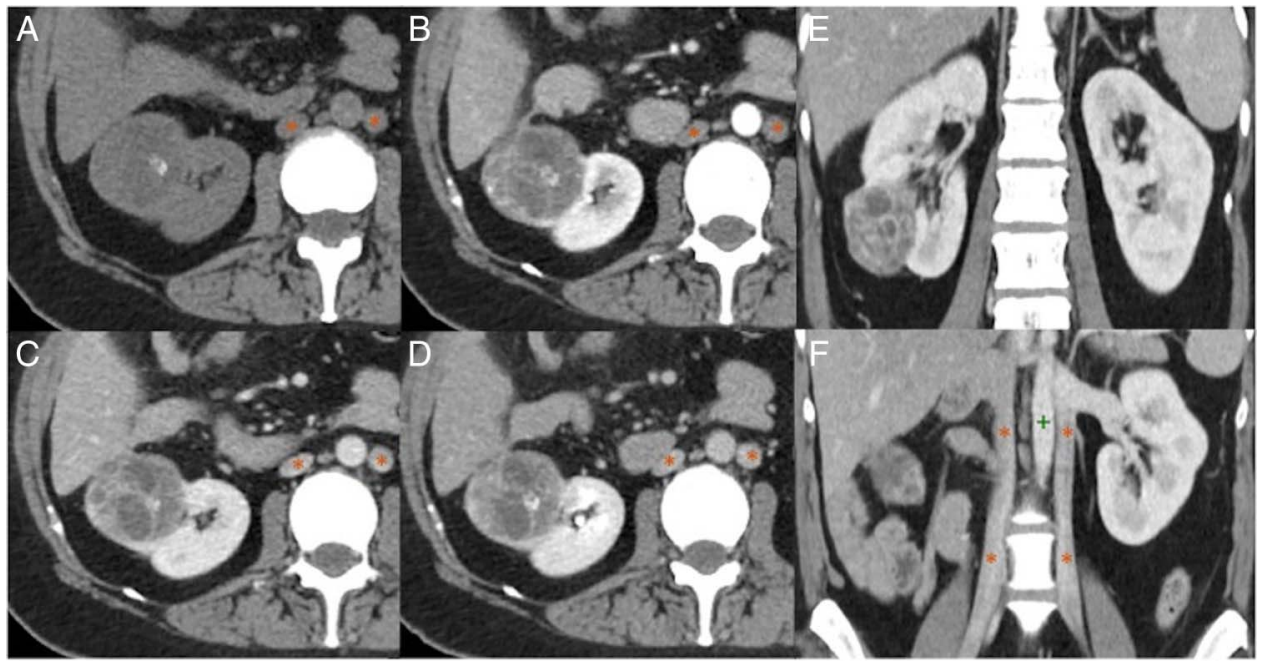

Figure 2 Abdominal $C T$ before $(A)$ and after $(B-F)$ intravenous contrast administration. (A) On axial unenhanced CT images, this right renal lesion shows well-defined limits, predominant hydric density and a few fine septal calcifications. (B-D) Axial and (E and F) coronal CT images after administration of intravenous contrast demonstrate the multiloculated morphology of this tumour with multiple cysts separated by multiple thick and irregular septa showing measurable enhancement (B-E). No solid nodules were detected. These features were consistent with a Bosniak type III lesion. This patient also showed inferior vena cava duplication, a rare congenital vascular anatomic variation $\left(^{*}\right)$.

and fat supressed T2-weighted images (figure 5), the renal lesion had no loss of signal intensity, excluding the presence of fat in the lesion. The wall and septa showed enhancement after the injection of gadolinium. (figure 6). The tumour had no restricted diffusion (figure 7 ).

Although there was easy access for percutaneous biopsy of this kidney lesion, which could give the preoperative diagnosis, this procedure was not performed because of its high falsenegative results on cystic lesions and also because of the risk of tumour seeding. So the patient underwent right partial nephrectomy with no previous biopsy.

\section{DIFFERENTIAL DIAGNOSIS}

The differential diagnosis of MCRCC includes benign lesions, such as mixed epithelial and stromal tumour of the kidney, cystic nephroma, multilocular cysts, haemorrhagic cysts and infection/abscess; as well as malignant neoplasms, such as other types of RCC with cystic/haemorrhagic/necrotic changes, extensively cystic RCC, tubulocystic carcinoma and clear cell papillary RCC.

\section{TREATMENT}

The patient underwent right partial nephrectomy with intraoperative histopathological analysis of the right kidney lesion specimen.

\section{OUTCOME AND FOLLOW-UP}

Macroscopic examination of the right partial nephrectomy surgical specimen showed complete excision of an encapsulated renal tumour, with a multilocular appearance presenting
Figure 3 Axial $(\mathrm{A})$ and coronal $(\mathrm{B})$ abdominal MR T2-weighted images showing a partial exophytic lesion in the lower third of the right kidney parenchyma, well-delineated by a hypointense rim, multiloculated, and composed of multiple hyperintense cysts separated by thick and irregular hypointense septa, without solid nodules.

Figure 4 (A) On T1-weighted images, this right renal neoplasm showing similar signal intensity to the adjacent renal parenchyma and a peripheral hypointense rim. On (A) in-phase and (B) out-of-phase T1-weighted images, the lesion has no signal loss, excluding the presence of intracellular fat component.
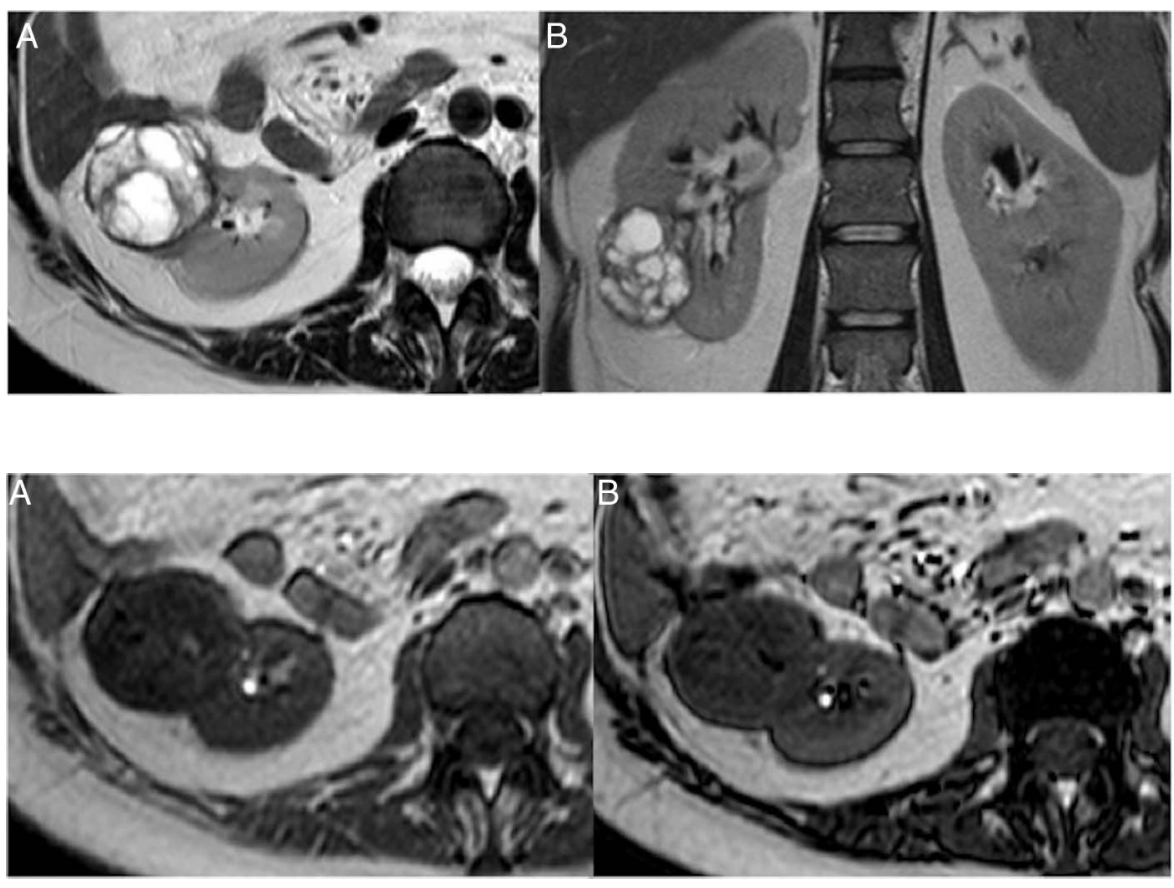

Morna Palmeiro M, et al. BMJ Case Rep 2016. doi:10.1136/bcr-2016-214386 


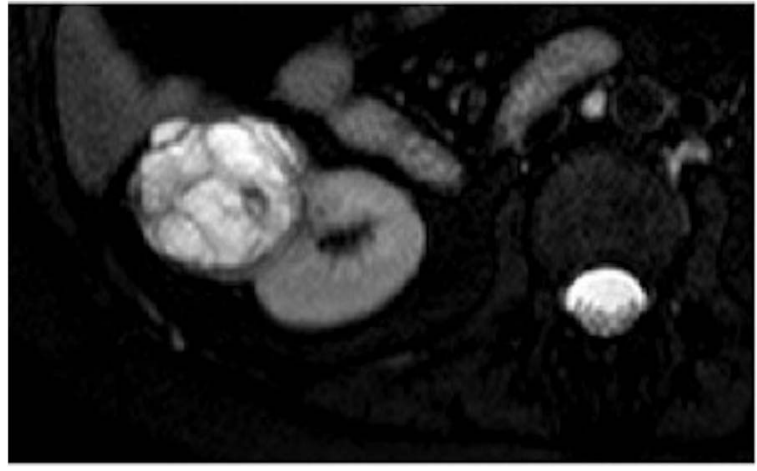

Figure 5 On fat supressed T2-weighted images, this renal lesion showing no signal intensity loss, excluding the presence of macroscopic fat.

multiple cysts of different sizes, corresponding to $70 \%$ of the tumour, separated by multiple thin fibrous septa, which constituted the tumour solid component, corresponding to the remaining $30 \%$ of the tumour (figure 8 ).

The microscopic examination revealed multiple cysts of different sizes and multiple fibrous septa (figure 9A). A thin epithelial layer of neoplastic clear cells with uniform nuclei and clear cytoplasm lined the cyst walls and fibrous septa (figure 9B).
These clear cells showed low Fuhrman grade. No solid expansible nodules were detected.

The final pathological diagnosis was multilocular cystic renal cell carcinoma of the right kidney, Fuhrman grade 1.

The patient recovered from surgery without complications, with a postoperative normal glomerular filtration rate. She stayed asymptomatic at 6-month follow-up, with no suspicious findings on the renal ultrasound performed at that time. An abdominopelvic CT is scheduled for 1-year follow-up.

\section{DISCUSSION}

MCRCC, also referred as multilocular clear cell RCC, is an uncommon cystic renal tumour that accounts for approximately $4 \%$ of all RCC. ${ }^{1}$

MCRCC commonly appears between the 2nd and 7th decades of life, being three times more frequent in males than in females. $^{2}$

This rare form of clear cell RCC usually has no associated symptoms, and frequently is detected incidentally. In some cases, it can present with gross haematuria, flank pain, palpable mass and abdominal discomfort. ${ }^{36}$

In the 2004 WHO guidelines, MCRCCs are histopathologically defined as well-defined multilocular cystic tumours, with multiple cysts of different sizes and multiple fibrous septa, covered by a layer of Fuhrman grade 1, and less commonly grade 2, neoplastic clear cells indistinguishable from low grade
Figure 6 On dynamic

contrast-enhanced images, the tumour showing enhancement of its wall and septa. No enhancing solid nodules were detected.

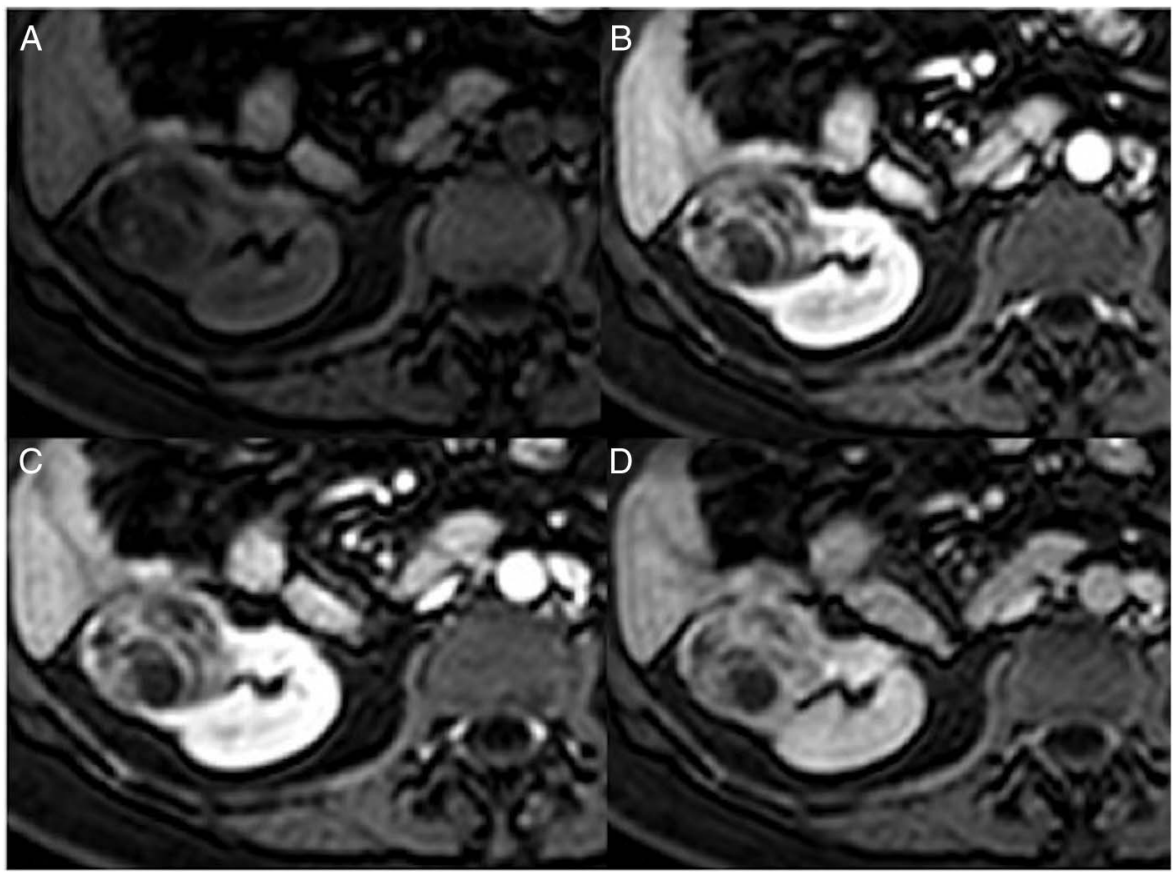

Figure 7 On diffusion study, this renal tumour was $(A)$ hypointense on high b values (b1000) and (B) hyperintense on the ADC map, showing no restricted diffusion.

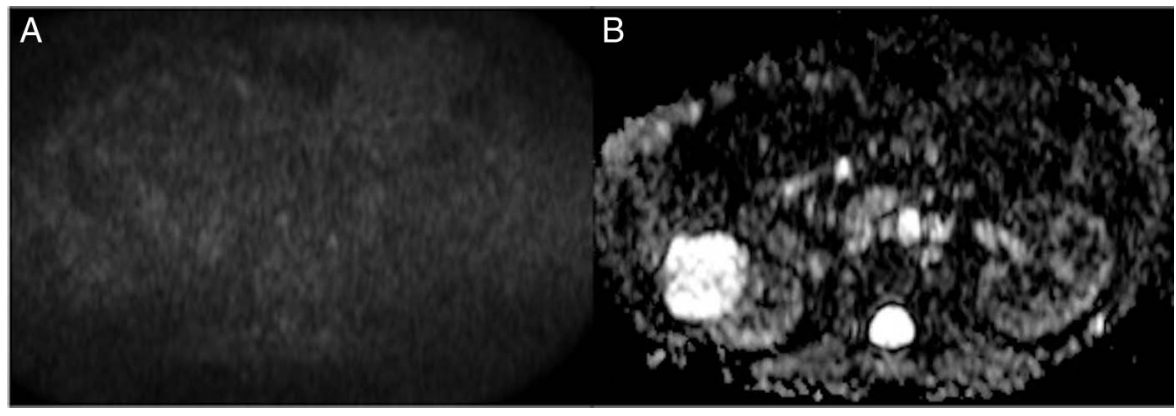




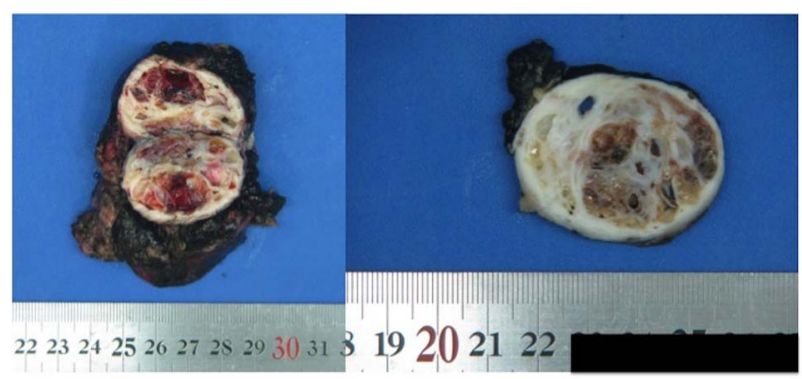

Figure 8 A photograph of the gross specimen of right partial nephrectomy showing complete excision of an encapsulated renal tumour, displaying a multilocular appearance with multiple cysts of different sizes, corresponding to $70 \%$ of the tumour, separated by multiple fibrous septa, which constitute the tumour solid component, corresponding to the remaining $30 \%$ of the tumour.

clear RCC, constituting the solid component of these neoplasms. The cysts are filled with gelatinous (serous or proteinaceous) and haemorrhagic fluid and no expansible solid nodules are seen. ${ }^{2} 67$

The increase in septa number and thickness and in the amount of neoplastic clear cells is correlated with the increase in complexity of MCRCC imaging appearances, ranging from probable benign lesion (Bosniak type IIF) to very suspicious lesions (Bosniak type IV). ${ }^{48}$

On ultrasound, MCRCC appears as well-circumscribed cystic or cystic-solid lesions, with thick walls, anechoic locules, or showing some hyperechoic debris, separated by hyperechoic thin or thick septa. On Doppler ultrasound evaluation, it may show increased blood flow in the cyst walls. ${ }^{9} 10$

MCRCC presentation on CT ranges from Bosniak IIF cystic lesions-with mildly thickened walls and multiple thin internal septations, both without measurable enhancement, and a few small nodular calcifications-to Bosniak IV cystic lesions, which are cystic masses with enhancing wall nodules or septa nodules. ${ }^{8} 11$ The most common CT appearance of MCRCC is in the form of Bosniak III cystic lesions, showing a complex cystic appearance with thick or irregular wall and septa with measurable enhancement, and variable amounts of calcifications, up to $20 \%$, without solid nodules. ${ }^{3} 1112$ These neoplasms are typically well-defined lesions, and the loss of this feature is suggestive of a higher nuclear grade tumour or an advanced stage.

Similar to CT, on MRI, MCRCCs may also show a spectrum of appearances, assuming more complexity with the increase of fibrous septa and neoplastic clear cell amount. ${ }^{13}$ T2 sequences are the best to depict the multiloculated morphology typical of these lesions, and better characterise their cysts, wall and septa. On both T1-weighted and T2-weighted images, MCRCCs typically demonstrate a hypointense rim, corresponding to a fibrous capsule and its disruption indicates a more aggressive and undifferentiated neoplasm. Signal intensity depends on their content (serous, proteinaceous or haemorrhagic), most commonly presenting isointense to the adjacent renal parenchyma on T1-weighted images and hyperintense on T2-weighted images. ${ }^{8}{ }^{14}$ On fat supressed and on in-phase and out-of-phase T1-weighted images, there is no loss of signal intensity, because these are non-fat containing lesions. On dynamic contrast-enhanced images, MCRCC shows enhancement of its solid component. ${ }^{8} 13 \quad 14$ These lesions do not commonly show restriction to diffusion, presenting a high mean ADC value, concordant with their typical hypocellularity. ${ }^{15}$

MCRCC cannot be distinguished from other multiloculated cystic renal tumours by imaging techniques. Hence, in the presence of a complex multicystic renal mass with measurable enhancement, it is important to be aware of this indolent and low grade form of RCC, so that a nephron-sparing procedure can be applied, with the patient's renal function preserved. ${ }^{4} 13$

MCRCCs behave like benign lesions, because of their characteristically low nuclear grade. These neoplasms have an excellent prognosis, with reports of neither metastasis nor progression. ${ }^{46}$

\section{Learning points}

- Multilocular cystic renal cell carcinoma (MCRCC) consists of a rare subtype of renal cell carcinoma (RCC).

- They commonly present as Bosniak type III cystic lesions.

- Most cases show Fuhrman nuclear grade 1.

- This form of RCC has low malignant potential and an excellent prognosis.

- Nephron-sparing surgery is the recommended treatment for MCRCC.

Acknowledgements The authors thank Dr Ricardo Fonseca, an experienced pathologist at our institution, who contributed with his knowledge to the histopathological diagnosis of this rare form of renal cell carcinoma.

Contributors MMP conducted the bibliographic research and wrote the case report. JLN performed the patient's CT and revised the case report. ALL carried out the patient's ultrasound and helped on the bibliographic research. JPCeS reported on the patient's MRI and revised the case report. All the authors contributed to this case report.

Competing interests None declared.

\section{Patient consent Obtained.}

Provenance and peer review Not commissioned; externally peer reviewed.
Figure 9 Photomicrograph of histological section reveals $(A)(H \& E$, $\times 100)$ multiple cysts of different sizes and multiple fibrous septa. (B) (H\&E, $\times 200)$ A thin epithelial layer of neoplastic clear cells with uniform nuclei and clear cytoplasm lined the cysts walls and fibrous septa. These clear cells showed low Fuhrman grade. No solid expansible nodules were detected.

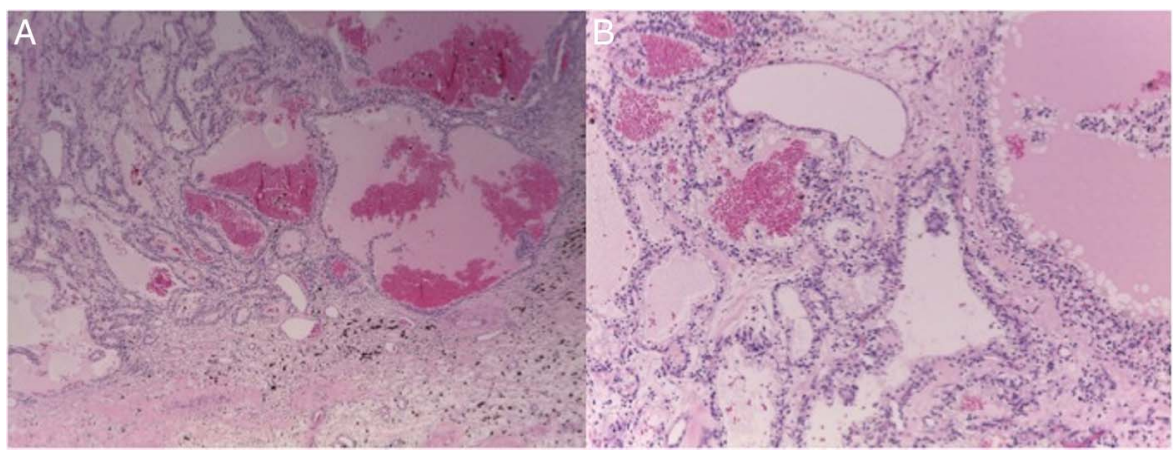

Morna Palmeiro M, et al. BMJ Case Rep 2016. doi:10.1136/bcr-2016-214386 


\section{REFERENCES}

1 Srigley JR, Delahunt B, Eble JN, et al., The ISUP Renal Tumor Panel. The International Society of Urological Pathology (ISUP) Vancouver classification of renal neoplasia. Am J Surg Pathol 2013;37:1469-89.

2 Eble JN, Sauter G, Epstein JI, et al. Pathology and genetics of tumours of the urinary system and male genital organs. Lyon, France: IARC Press, 2004.

3 Katabathina VS, Gangadhar K, Vinu-Nair S, et al. Cystic renal neoplasms in adults: current imaging update. App/ Radiol 2015;2015:23-33.

4 Hora M, Hes 0 , Michal M, et al. Extensively cystic renal neoplasms in adults (Bosniak classification II or III)—possible "common" histological diagnoses: multilocular cystic renal cell carcinoma, cystic nephroma, and mixed epithelial and stromal tumor of the kidney. Int Urol Nephrol 2005;37:743-50.

5 Suzigan S, López-Beltrán A, Montironi R, et al. Multilocular cystic renal cell carcinoma: a report of 45 cases of kidney tumor of low malignant potential. Am J Clin Pathol 2006;125:217-22.

6 Kuroda N, Ohe C, Mikami S, et al. Multilocular cystic renal cell carcinoma with focus on clinical and pathobiological aspects. Histol Histopathol 2012;27:969-74.

7 Wahal SP, Mardi K. Multilocular cystic renal cell carcinoma: a rare entity with review of literature. J Lab Physicians 2014;6:50-2.
8 Hindman NM, Bosniak MA, Rosenkrantz AB, et al. Multilocular cystic renal cell carcinoma: comparison of imaging and pathologic finding. AJR Am J Roentgenol 2012;198:W20-6.

9 Chen $S$, Jin B, Xu L, et al. Cystic renal cell carcinoma: a report of 67 cases including 4 cases with concurrent renal cell carcinoma. BMC Urol 2014;14:87.

$10 \mathrm{Kim} \mathrm{JC}$, Kim KH, Lee JW. CT and US findings of multilocular cystic renal cell carcinoma. Korean J Radiol 2000;1:104-9.

11 Wood CG III, Stromberg LJ III, Harmath CB, et al. CT and MR imaging for evaluation of cystic renal lesions and diseases. Radiographics 2015;35: 125-41.

12 Prasad SR, Humphrey PA, Catena JR, et al. Common and uncommon histologic subtypes of renal cell carcinoma: imaging spectrum with pathologic correlation. Radiographics 2006;26:1795-806; discussion 1806-10.

13 Israel GM, Bosniak MA. How I do it: evaluating renal masses. Radiology 2005;236:441-50.

14 Gurel S, Narra V, Elsayes KM, et al. Subtypes of renal cell carcinoma: MRI and pathological features. Diagn Interv Radiol 2013;19:304-11.

15 Muglia VF, Westphalen AC. Bosniak classification for complex renal cysts: history and critical analysis. Radiol Bras 2014;47:368-73.

Copyright 2016 BMJ Publishing Group. All rights reserved. For permission to reuse any of this content visit

http://group.bmj.com/group/rights-licensing/permissions.

BMJ Case Report Fellows may re-use this article for personal use and teaching without any further permission.

Become a Fellow of BMJ Case Reports today and you can:

- Submit as many cases as you like

- Enjoy fast sympathetic peer review and rapid publication of accepted articles

- Access all the published articles

- Re-use any of the published material for personal use and teaching without further permission

For information on Institutional Fellowships contact consortiasales@bmjgroup.com

Visit casereports.bmj.com for more articles like this and to become a Fellow 